\title{
Recent aspects of oxide thermoelectric materials for power generation from mid-to-high temperature heat source
}

\author{
Michitaka OHTAKI ${ }^{\dagger}$ \\ Department of Molecular and Material Sciences, Interdisciplinary Graduate School of Engineering Sciences, \\ Kyushu University, Fukuoka 816-8580
}

Rapid progress in thermoelectric performance of oxide materials has been conducted virtually exclusively in Japan, resulting in more than 10 times increase in the $Z T$ values of oxides within the last two decades. This has caused a revolutionary change in the guiding principles of thermoelectric materials research, in which oxide materials had been disregarded as a potential candidate until early 1990s. Promising oxide thermoelectric materials having been discovered include $\mathrm{CaMnO}_{3}$-based perovskites, Al-doped $\mathrm{ZnO}$, layered cobalt oxides represented by $\mathrm{NaCo}_{2} \mathrm{O}_{4}$ and $\mathrm{Ca}_{3} \mathrm{Co}_{4} \mathrm{O}_{9}$, and $\mathrm{SrTiO}_{3}$-related phases. This paper reviews the current aspects of oxide thermoelectric materials, and some strategies of nanostructure control for selective reduction of the lattice thermal conductivity (selective phonon scattering) in bulk oxide ceramics will also be discussed.

(O2011 The Ceramic Society of Japan. All rights reserved.

Key-words : Thermoelectric power generation, Waste heat recovery, Oxide, Seebeck coefficient

[Received July 12, 2011; Accepted July 26, 2011]

\section{Introduction}

A temperature gradient across a solid (except superconducting materials) generates an electrical voltage between the hot and cold ends. This phenomenon, discovered in 1821 and named the Seebeck effect, has extensively been utilized in thermocouples for temperature measurement. While the voltage (thermoelectromotive force, TMF) generated by metals is generally less than $50 \mu \mathrm{V} / \mathrm{K}$, semiconductors can generate the TMF of several hundreds of $\mu \mathrm{V} / \mathrm{K}$. Since $n$ - and $p$-type semiconductors generate the TMF of the opposite signs, and thereby doubles the voltage when combined, a semiconductor element (unicouple) as shown in Fig. 1 is fabricated as a unit component, and is connected in series to assemble thermoelectric modules in practical. This technology for direct conversion of heat to electricity is called thermoelectric conversion or thermoelectric power generation.

The energy conversion efficiency of the thermoelectric power generation is governed by the figure-of-merit, $Z\left[\mathrm{~K}^{-1}\right]$, of materials constituting the unicouple as

$$
Z=\frac{S^{2} \sigma}{\kappa}=\frac{S^{2} \sigma}{\kappa_{\mathrm{el}}+\kappa_{\mathrm{ph}}}
$$

where $S[\mathrm{~V} / \mathrm{K}]$ is the Seebeck coefficient, $\sigma[\mathrm{S} / \mathrm{m}]$ is the electrical conductivity, $\kappa[\mathrm{W} / \mathrm{mK}]$ is the thermal conductivity, $\kappa_{\mathrm{el}}$ and $\kappa_{\mathrm{ph}}$ are the carrier and phonon components of $\kappa$, respectively. ${ }^{1)}$ Since the conversion efficiency is directly determined by $Z$ multiplied by average operating temperature, $T$, so-called dimensionless figure-of-merit, $Z T$, materials with larger $S$, higher $\sigma$, and lower $\kappa$ are desired. The efficiency reaches approximately $10 \%$ at $Z T=1$, and hence $Z T \geq 1$ is generally accepted as a criterion for practical applications. However, the three physical parameters comprising $Z$ are all the functions of the carrier concentration, $n$, as depicted in Fig. 2; while $S$ and $\sigma$

\footnotetext{
Corresponding author: M. Ohtaki; E-mail: ohtaki@mm.kyushu-u. ac.jp
}

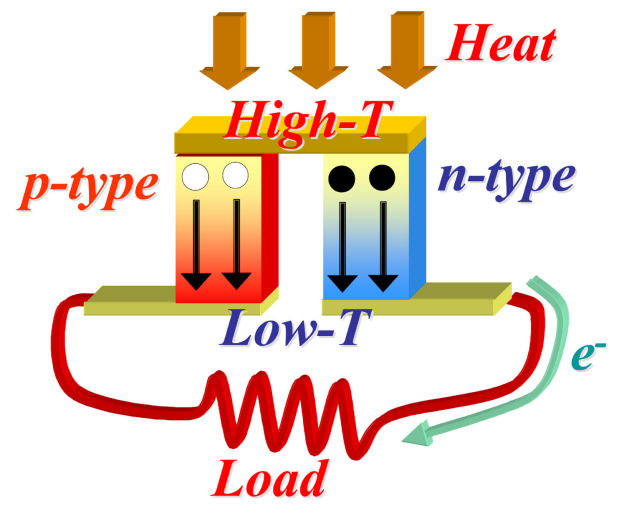

Fig. 1. (Color online) Schematic illustration of a thermoelectric unicouple.

vary inversely each other, $\sigma$ and $\kappa$ change in the similar way (the Wiedemann-Franz law). Thus, improvement in $Z T$ is not an easy task.

According to classical semiconductor theories assuming itinerant electrons in the wide conduction band, the numerator of $Z, S^{2} \sigma$ (called power factor), takes the maximum at a carrier concentration in the order of $10^{19} / \mathrm{cm}^{3}$, regardless of materials. If the optimal $n$ is uniquely determined, all what we can do for higher $Z T$ is to increase the carrier mobility to obtain higher $\sigma$ at the fixed $n$, and to decrease $\kappa_{\mathrm{ph}}$ in $\kappa$. Conventional thermoelectric materials developed until 1990s having been selected by these guiding principles are intermetallic compounds and alloys with covalent bonding characters (for higher mobility), and consist of heavy elements (for lower $\kappa_{\mathrm{ph}}$ ) such as $\mathrm{Bi}, \mathrm{Te}, \mathrm{Pb}$. Representative materials are $\mathrm{Bi}_{2} \mathrm{Te}_{3}$ for room temperature up to $200^{\circ} \mathrm{C}, \mathrm{PbTe}$ for $400-600^{\circ} \mathrm{C}$, and $\mathrm{Si}-\mathrm{Ge}$ alloys for $400-1000^{\circ} \mathrm{C}$ as shown in Fig. 3. However, these materials are incapable of wide commercialization because of their shortcomings such as poor durability at high temperature in air, low abundance and high cost of the comprising elements, and high toxicity. 

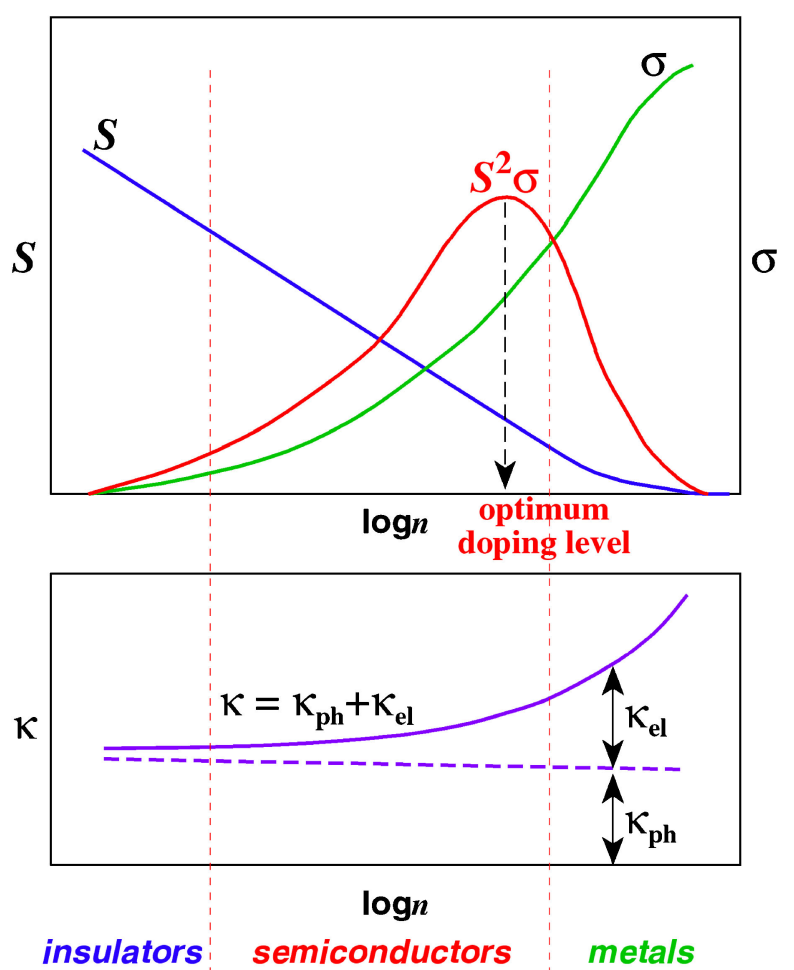

Fig. 2. (Color online) The carrier concentration dependence of $S, \sigma$, and $\kappa$.



Fig. 3. (Color online) Typical waste heat and operating temperature ranges of various thermoelectric materials.

Metal oxides are ionic compounds consisting of metal cations and oxygen anions alternately placing with the Coulombic attracting interaction between them. Since the metal-oxygen bonds are largely polarized, conducting electrons tend to localize on the positively charged metal cations. Moreover, overlapping of atomic orbitals between the atoms is smaller than that in the covalent compounds. These characters lead to the carrier mobility of oxides generally $2-3$ orders lower than those of $\mathrm{Si}$ and other covalent compounds. Moreover, large bonding energies of the ionic bonds and the small atomic mass of oxygen give a high velocity of the elastic waves propagating the crystal lattice of oxides, yielding a high lattice thermal conductivity, $\kappa_{\mathrm{ph}}$. These inherent characters of metal oxides are obviously against the conventional guiding principles for higher $Z T$, and thus metal oxides have been totally disregarded in the history of thermoelectric materials until the early 1990s.

In mid 1990s, however, emerging new guiding principles stimulated the researches for novel materials including oxides. Boosted by the global environment issues and carbon dioxide mitigation problems, oxide thermoelectric materials, which are highly durable at high temperature in air, non-toxic, low cost and minimal in environment impact, are becoming of more and more importance with aiming at recuperation of decentralized waste heat energy for higher energy efficiency. In this review, a landscape of oxide thermoelectric materials covering a wide variety of substances will be given with recent aspects of materials researches.

\section{High mobility oxides}

In 1991, the authors started to investigate an ability of oxide materials for thermoelectric applications. We first focused on $\mathrm{In}_{2} \mathrm{O}_{3}$-based oxides, in which $\mathrm{In}_{2} \mathrm{O}_{3}-\mathrm{SnO}_{2}$ complex oxides have been well known as ITO (Indium-Tin-Oxide), one of the most highly conductive oxides for transparent electrodes in many industrial applications. In the systematic study on the thermoelectric properties of $\mathrm{In}_{2} \mathrm{O}_{3}$-based complex oxides, $\mathrm{In}_{2} \mathrm{O}_{3} \cdot \mathrm{SnO}_{2}$ was revealed to show a largest power factor of $1.6 \times 10^{-4}$ $\mathrm{W} \mathrm{m}^{-1} \mathrm{~K}^{-2}$ and $Z=0.04 \times 10^{-3} \mathrm{~K}^{-1}$ at $1000^{\circ} \mathrm{C}$. The highest $Z T$ value was 0.06 , being of course much lower that those shown by conventional non-oxide materials. However, the $Z T$ value appeared to further increase at higher temperature, suggesting a possibility of heat-resistant oxide semiconductors for hightemperature thermoelectric power generation. $\left.{ }^{2}\right)$

Recently, addition of Ge to $\operatorname{In}_{2} \mathrm{O}_{3}$ was reported to increase $\sigma$ by electron doping by the substitution of $\mathrm{Ge}^{4+}$ for $\mathrm{In}^{3+}$, while precipitation of fine particles of the $\operatorname{In}_{2} \mathrm{Ge}_{2} \mathrm{O}_{7}$ impurity phase efficiently reduced $\kappa$, resulting in $Z T=0.45$ at $1273 \mathrm{~K}$ at the composition of $\operatorname{In}_{1.8} \mathrm{Ge}_{0.2} \mathrm{O}_{3}{ }^{3)}$

\section{Oxides with hopping conduction mechanism}

In ionic crystals such as oxides, conduction electrons (or positive holes) polarize the surrounding crystal lattice by strong electron-lattice interactions, localizing themselves on the lattice points with inducing lattice distortion. Such localized electrons are called small polarons, and travel by a hopping mechanism accompanied by the surrounding lattice distortion. This mechanism results in the carrier mobility much lower than that for the band conduction. Whereas the upper limit of the small polaron hopping in oxides is considered as low as $1-0.1 \mathrm{~cm}^{2} / \mathrm{Vs}$, some oxides with small polaron hopping mechanism have been revealed to show relatively high thermoelectric performance considering their low mobility values.

$\mathrm{La}_{1-x} \mathrm{Sr}_{x} \mathrm{CrO}_{3}$ is a highly conductive perovskite-type oxide with high thermal durability, and has been widely used such as interconnectors in solid oxide fuel cells. The conduction mechanism of the oxide was reported to be small polaron hopping with thermally activated carrier mobility; $\log (\sigma T)$ proportional to $1 / T$, which indicating thermally activated $\sigma$, and nearly temperature-independent $S$ values were observed. ${ }^{4)}$ The $\sigma$ values of $10^{1}-10^{2} \mathrm{~S} / \mathrm{cm}$ over the wide temperature range from room temperature up to $1800^{\circ} \mathrm{C}$ with the positive $S$ values of $200-300 \mu \mathrm{V} / \mathrm{K}$ appear to be promising for thermoelectric applications. The thermoelectric performance of $\mathrm{La}_{0.85} \mathrm{Sr}_{0.15} \mathrm{CrO}_{3}$ was reported as $Z T=0.14$ at $1600 \mathrm{~K}^{5}{ }^{5}$ Interestingly, despite the hopping conduction with a constant carrier concentration, the positive $S$ values linearly increased with increasing temperature. 

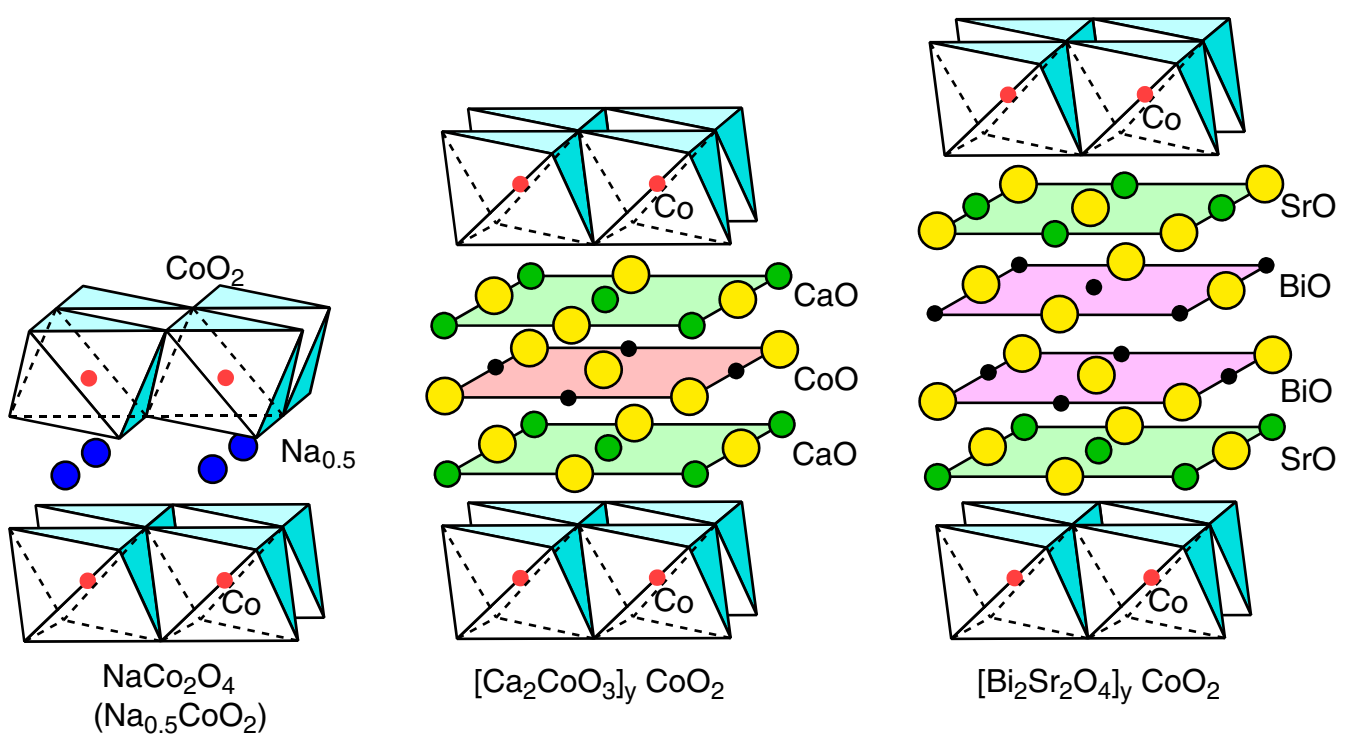

Fig. 4. (Color online) Crystal structures of layered cobalt oxides. ${ }^{18)}$

A similar behaviour was reported on $\mathrm{B}_{x} \mathrm{C}$ and is explained by hopping between non-equivalent sites. ${ }^{6}$

The authors have studied on another perovskite-type oxide $\mathrm{CaMnO}_{3}$ showing the conduction mechanism similar to that of $\mathrm{La}_{1-x} \mathrm{Sr}_{x} \mathrm{CrO}_{3}$. ${ }^{7-9)}$ Substitution of the $\mathrm{Ca}$ sites with $\mathrm{Bi}$ increased the $\sigma$ values at room temperature more than 3 orders of magnitudes; $\left(\mathrm{Ca}_{0.9} \mathrm{Bi}_{0.1}\right) \mathrm{MnO}_{3}$ showed the power factors of $2 \times$ $10^{-4} \mathrm{~W} / \mathrm{mK}^{2}$ or larger. ${ }^{7), 8)}$ Moreover, $\mathrm{Ca}\left(\mathrm{Mn}_{0.9} \mathrm{In}_{0.1}\right) \mathrm{O}_{3}$ maintained the power factor of $2-3.5 \times 10^{-4} \mathrm{~W} / \mathrm{mK}^{2}$ over the range of room temperature up to $900^{\circ} \mathrm{C}$, and the largest values of $Z=0.14 \times 10-3 \mathrm{~K}^{-1}$ and $Z T=0.16$ were obtained at $900^{\circ} \mathrm{C} .{ }^{9)}$ A good correlation was found between the hopping carrier mobility and the ionic radii of the substituent cations, suggesting that $\operatorname{In}^{3+}$ with the largest ionic radius in this study resulted in the longest intersite distance and hence the highest hopping mobility. It should be noted that the thermoelectric performance of the oxide having a carrier mobility of as low as $\sim 1 \mathrm{~cm}^{2} / \mathrm{Vs}$ is higher than those of many high mobility oxides. Recently, $\mathrm{CaMnO}_{3}$ based oxides have been revisited, and a refined composition with improved performance was employed as $n$-type leg of oxide thermoelectric modules. ${ }^{10), 11)}$ Furthermore, simultaneous substitution at both $\mathrm{Ca}$ and $\mathrm{Mn}$ sites was reported to attain $Z T=0.21 .{ }^{12)}$

\section{Layered cobalt oxides}

A number of metal oxides, including well-known layered cuprate high- $T_{\mathrm{c}}$ superconductors, are known to have layered crystal structures. The thermal conductivity of layer-structured materials is expected to be significantly low due to phonon scattering at the interfaces between the layers. Moreover, drastic improvement of the thermoelectric performance was theoretically predicted for quantum-well structures. ${ }^{13), 14)}$ These anticipations have attracted much interest to metal oxides with layered crystal structures.

In alloys and solid solutions of rare-earth elements known as "heavy fermion" systems, a strong electron correlation between localized $f$-electrons and itinerant conduction electrons makes electronic specific heat, i.e. density-of-state 100-1000 times larger than normal values, and accordingly, exceptionally large Seebeck coefficients were observed. While strongly correlated electron systems in oxides are typically observed in high- $T_{\mathrm{c}}$ superconducting cuprates, no promising materials in thermoelectrics has been found in this family. However, a series of layered cobalt oxides related to high- $T_{\mathrm{c}}$ superconductors were discovered to show outstandingly high $p$-type thermoelectric performance in oxides.

The first report on a large Seebeck coefficient in $\mathrm{NaCo}_{2} \mathrm{O}_{4}{ }^{15}$ ) has triggered extensive studies on layered cobalt oxides. ${ }^{16)-18)}$ As shown in Fig. 4, a common feature of this family is the $\mathrm{CdI}_{2}$-type two-dimensional hexagonal $\mathrm{CoO}_{2}$ layers consisting of edgesharing $\mathrm{CoO}_{6}$ octahedra. While the $\mathrm{CuO}_{2}$ layers in the superconducting cuprates consist of planar square lattices of $\mathrm{Cu}-\mathrm{O}$, the $\mathrm{CoO}_{2}$ layers in the layered cobalt oxides consist of planar triangle lattices of $\mathrm{Co}-\mathrm{Co}$, suggesting a magnetic frustration in the spin configuration of conduction electrons. In $\mathrm{NaCo}_{2} \mathrm{O}_{4}, \mathrm{CoO}_{2}$ layers and $\mathrm{Na}$ layers are alternately stacking along the $c$-axis. While the $\mathrm{CoO}_{2}$ layers are considered to work as the conduction path of electrons, the $\mathrm{Na}$ layers are largely nonstoichiometric, $30-50 \%$ of the $\mathrm{Na}$ sites being deficient as $\mathrm{Na}_{x} \mathrm{CoO}_{2}(x \sim 0.5)$. The outstanding thermoelectric performance of this oxide is attributed to its anomalously large thermopower considering the high carrier concentration, and its low thermal conductivity comparable to that of glass-like materials. A strong electron correlation due to spin fluctuation was proposed as the origin of the large thermopower, and accordingly a measured value of the electronic specific heat of the oxide was $40-50 \mathrm{~mJ} / \mathrm{mol} \mathrm{K}^{-2}$, being as large as those observed on "heavy fermion" systems. ${ }^{19)}$

Instead of the $\mathrm{Na}$ layers, $\mathrm{Ca}_{3} \mathrm{Co}_{4} \mathrm{O}_{9}$ (Ca-349, Fig. 4 middle) has $\mathrm{Ca}_{2} \mathrm{CoO}_{3}$ layers with the triple rock salt structure, and $\mathrm{Bi}_{2} \mathrm{Sr}_{2} \mathrm{Co}_{2} \mathrm{O}_{y}$ (BC-222, Fig. 4 right) has $\mathrm{Bi}_{2} \mathrm{Sr}_{2} \mathrm{O}_{4}$ layers with the quadruple rock salt structure. In these oxides, alternate stacking of hexagonal $\mathrm{CoO}_{2}$ layers and rectangular rock salt layers causes a peculiar lattice misfit, in which only the $b$-axis length is incommensurate between the adjacent layers. Accordingly, the chemical formula such as $\left[\mathrm{Ca}_{2} \mathrm{CoO}_{3}\right]_{y} \mathrm{CoO}_{2}(y \sim 0.62)$, $\left[\mathrm{Bi}_{0.87} \mathrm{SrO}_{2}\right]_{2}\left[\mathrm{CoO}_{2}\right]_{1.82}$, or $\left[\mathrm{Bi}_{2} \mathrm{Sr}_{2} \mathrm{O}_{4}\right]_{y} \mathrm{CoO}_{2}$ would be more adequate to describe these oxides. ${ }^{20)-23)}$ The thermoelectric properties of these oxides measured on whiskers (ribbon-like single crystals) of 50-200 mm width along the in-plane direction revealed the largest $Z T=1.2-2.7$ for $\mathrm{Ca}-349$ at $873 \mathrm{~K},{ }^{24)}$ and $Z T \geq 1.1$ for $\mathrm{BC}-222$ at $1000 \mathrm{~K}^{23)}$ 




Fig. 5. The dimensionless figure-of-merit of single crystals of layered cobalt oxides. ${ }^{31)}$

As shown in Fig. 5, the in-plane $Z T$ values of single crystals of these layered cobalt oxides exceed unity at $700-1000 \mathrm{~K},{ }^{23)-25)}$ confirming that the intrinsic properties of these oxides satisfy the criteria for practical applications. However, a strong anisotropy in the properties and the crystal growth lead to the performance of bulk ceramic samples several times lower than that of single crystals. Although an improvement in ceramic processing resulted in $Z T=0.7-0.8$ for polycrystalline $\mathrm{NaCoO}_{2},{ }^{26), 27)}$ highly mobile $\mathrm{Na}$ ions still remain problematic as they readily form insulating phases by the reaction with water and $\mathrm{CO}_{2}$ in the atmosphere. Since $\mathrm{Ca}-349$ is much more strongly anisotropic, the largest $Z T$ values for polycrystalline Ca-349 remain as low as $\sim 0.3{ }^{28)}$ Further improvement in processing techniques is anticipated in order to derive the outstanding thermoelectric performance of the single crystals also from practical bulk polycrystalline ceramics.

\section{5. $\mathrm{SrTiO}_{3}$-based perovskite-type oxides}

Strontium titanate $\mathrm{SrTiO}_{3}$ crystallizes in the cubic perovskite structure at room temperature, while most of the "perovskitetype" oxides are non-cubic. The oxide is essentially a band insulator with an empty conduction band consisting mainly of Ti3d orbitals and the filled valence band consisting of $\mathrm{O} 2 p$ orbitals. However, heat treatment in reducing atmosphere can form oxygen vacancy and thereby inject electrons into the conduction band, resulting in high electrical conductivity. Since the bottom of the conduction band consists of 3 -fold degenerated narrow Ti3d- $t_{2 \mathrm{~g}}$ orbitals, ${ }^{29)}$ the conduction electrons were expected to have relatively large effective mass. Intensive electron doping under the reducing conditions resulted in the power factor values of $\sim 10 \times 10^{-4} \mathrm{~W} / \mathrm{mK}^{2}$ for polycrystalline samples, ${ }^{30), 31)}$ and $20-30 \times 10^{-4} \mathrm{~W} / \mathrm{mK}^{2}$ for single crystal. ${ }^{32)}$ However, the thermal conductivity of the oxide is as high as $6-10 \mathrm{~W} / \mathrm{mK}$ at room temperature due to its simple crystal structure and the light constituting elements, limiting the figureof-merit of the oxide as $Z T=0.1-0.2$. Ohta et al. obtained $Z T=0.27$ on $\mathrm{Nb}$-doped $\left(3.3 \times 10^{20} \mathrm{~cm}^{-3}\right) \mathrm{SrTiO}_{3}$ single crys$\mathrm{tal}^{33)}$ and $Z T=0.37(1000 \mathrm{~K})$ on $20 \% \mathrm{Nb}$-doped $(4.0 \times$ $\left.10^{21} \mathrm{~cm}^{-3}\right) \mathrm{SrTiO}_{3}$ epitaxial thin film. ${ }^{34)}$ Moreover, polycrystalline samples were confirmed to show a good performance of $Z T=0.35$ at $1000 \mathrm{~K},{ }^{35)}$ comparable to that of high-quality thin films. While grain boundaries in the polycrystalline samples strongly deteriorate the performance at low temperature, the influence is considered to become negligible at high temperature $\geq 700 \mathrm{~K}$. The $\mathrm{Nb}$ doping to $\mathrm{SrTiO}_{3}$ expands the crystal lattice and extends the Ti-Ti interatomic distance, leading to larger effective mass due to increased localization of the carrier electrons. This influence may compensate a decrease in the Seebeck coefficient due to the carrier doping, and thereby relatively large thermopower would be maintained even at high carrier concentrations.

The major problem of the $\mathrm{SrTiO}_{3}$-based oxides is that the reducing conditions are necessary for the $n$-type doping; oxidative atmosphere such as air will eliminate the carriers at high temperature. This drawback strictly limits the application of the oxide in vacuum or inert atmosphere. Practical use of the oxide will require stabilization of the doped carriers such as antioxidizing surface protection.

\section{ZnO-based oxides}

The localized characters of the electronic carriers in oxides can be exploited when the carriers with large effective masses can be heavily doped, thereby realizing large $S$ and high $\sigma$ simultaneously; the layered cobalt oxides and Ti-based oxides can be classified into this category. Another approach may be to reduce the ionicity of the metal-oxygen bonds in oxides in order to increase the carrier mobility. ZnO-based thermoelectric materials can be one of the examples of this strategy. ${ }^{36)-40)}$

Zinc oxide is a wide band gap semiconductor with a direct band gap of 3.2-3.5 eV. Zinc has relatively large electronegativity as a metal, resulting in the less polarized $\mathrm{Zn}-\mathrm{O}$ bond compared to other metal-oxygen bonds in metal oxides. Moreover, although the ratio of the ionic radii of $\mathrm{Zn}^{2+}$ and $\mathrm{O}^{2-}$ geometrically requires 6-fold coordination of $\mathrm{O}^{2-}$ around $\mathrm{Zn}^{2+}, \mathrm{Zn}^{2+}$ prefers 4-fold coordination in reality, and hence $\mathrm{ZnO}$ crystallizes in the wurzite structure consisting of apex-sharing $\mathrm{ZnO}_{4}$ tetrahedra, the packing density of the ions being much less than that of the closest packing. According to this coordination structure, the orbitals of valence electrons of $\mathrm{Zn}$ in $\mathrm{ZnO}$ can be regarded as $s p^{3}$ hybrid similar to that of $\mathrm{C}$ in organic compounds, suggesting a large covalency of the chemical bonds in the oxide. This peculiar coordination structure as oxide also restricts the elements and their solubility limits for substitution at the $\mathrm{Zn}$ sites in $\mathrm{ZnO}$.

Non-doped bulk $\mathrm{ZnO}$ is an $n$-type semiconductor showing increasing $\sigma$ with increasing temperature. However, a small amount of $\mathrm{Al}$ doping increases $\sigma$ more than 3 orders of magnitude at room temperature, and changes the conduction behavior from semiconducting to metallic with $\mathrm{d} \rho / \mathrm{d} T>0$. Whereas the thermoelectric performance becomes maximum at the composition of $x=0.02$ in $\mathrm{Zn}_{1-x} \mathrm{Al}_{x} \mathrm{O},{ }^{36), 37)}$ the solubility limit of $\mathrm{Al}$ in $\mathrm{ZnO}$ is lower than $2 \mathrm{~mol} \%$, and excess $\mathrm{Al}$ forms fine $\mathrm{ZnAl}_{2} \mathrm{O}_{4}$ spinel phase in the samples at $x \geq 0.01 .^{37), 41)} \mathrm{A}$ ceramic sample of $\mathrm{Zn}_{0.98} \mathrm{Al}_{0.02} \mathrm{O}$ showed large power factors of $10-18 \times 10^{-4} \mathrm{~W} / \mathrm{mK}^{2}$ over a wide temperature range, ${ }^{37)}$ these values being comparable to that of $\mathrm{Si}-\mathrm{Ge}$ alloys employed in radioactive thermoelectric generators for space applications. ${ }^{42)}$

The carrier mobility of $\mathrm{ZnO}$ at room temperature was reported as $\sim 200 \mathrm{~cm}^{2} /$ Vs for single crystal ${ }^{43)}$ and $80 \mathrm{~cm}^{2} /$ Vs for Al-doped ceramic sample. ${ }^{37)}$ These values are comparable to that of $\mathrm{SnO}_{2}$ $\left(240 \mathrm{~cm}^{2} / \mathrm{Vs}\right.$ for single crystal), and are one of the largest values observed in oxides. Nevertheless, the light constituting elements and strong interatomic bonding in $\mathrm{ZnO}$ lead to a high Debye temperature of $\theta_{\mathrm{D}}=416 \mathrm{~K}$, and hence a high sound velocity of acoustic phonons carrying heat. Accordingly, the $\kappa$ values of $\mathrm{ZnO}$ are very high compared to other thermoelectric materials, $54 \mathrm{~W} / \mathrm{mK}$ for single crystal (along the $c$-axis) ${ }^{44)}$ and $40 \mathrm{~W} / \mathrm{mK}$ for polycrystalline samples ${ }^{37)}$ at room temperature. These high 


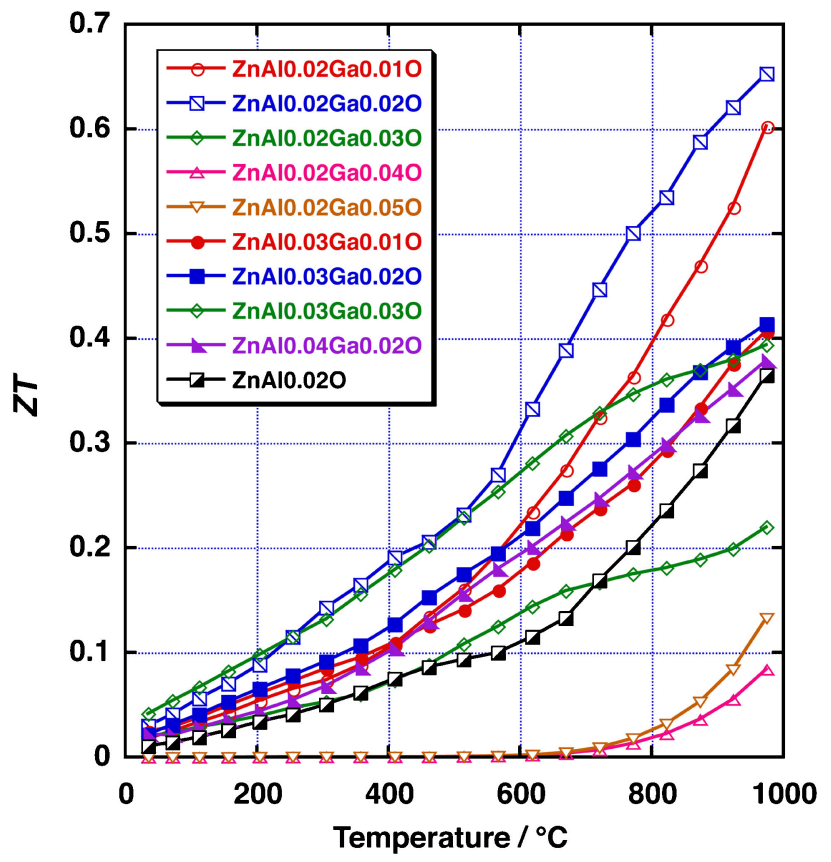

Fig. 6. (Color online) Dimensionless figure-or-merit, $Z T$, of $\mathrm{Zn}_{1-x-y^{-}}$ $\mathrm{Al}_{x} \mathrm{Ga}_{y} \mathrm{O}{ }^{45)}$

$\kappa$ values limit the thermoelectric performance of the oxide as $Z=0.24 \times 10^{-3} \mathrm{~K}^{-1}, Z T=0.30$ at $1273 \mathrm{~K}$. However, these values are still the largest among $n$-type oxides.

Estimating the electron thermal conductivity, $\kappa_{\mathrm{el}}$, by the Wiedemann-Franz law, the phonon thermal conductivity, $\kappa_{\text {ph }}$, was revealed to be predominant in the total $\kappa$ of the oxide. The phonon thermal conductivity of $\mathrm{ZnO}$ can be efficiently reduced by doping $\mathrm{Ga}$ and $\mathrm{In}$, group 13 elements heavier than $\mathrm{Al}^{38)}$ and by making solid solutions with $\mathrm{MgO}^{39)}$ and $\mathrm{NiO}^{40)}$ In these cases, however, mass fluctuations introduced by atomic substitution at the lattice points scatter not only phonons but also electrons. Consequently, the $\sigma$ values unfavourably decreased and improvement in $Z T$ was unsuccessful. Fortunately, if an element with electronegativity similar to $\mathrm{Zn}$ is introduced, deterioration of the electrical properties was relatively small. ${ }^{40)}$ This suggests that kph can be selectively reduced by carefully choosing the scattering centers.

Very recently, we have carried out co-doping of $\mathrm{Al}$ and $\mathrm{Ga}$ to $\mathrm{ZnO}$, and successfully reduced the $\kappa$ value of the oxide. The thermoelectric performance of the oxide was thereby markedly improved by the co-doping, obtaining $Z T=0.47$ at $1000 \mathrm{~K}$ and $Z T=0.65$ at $1273 \mathrm{~K}$ for $\mathrm{Zn}_{0.96} \mathrm{Al}_{0.02} \mathrm{Ga}_{0.02} \mathrm{O}^{45}$ as shown in Fig. 6 . This is the highest $Z T$ values so far reported on bulk $n$-type oxides.

\section{Concluding remarks}

As discussed above, while some $p$-type oxides have achieved $Z T=1$ in single crystal form, the performance of practical polycrystalline bulk oxide materials is still insufficient. Even so, development of oxide thermoelectric modules aiming at potential market is also in progress. One of the recent topics is development of pipe-type thermoelectric modules by Funahashi et al. in AIST, Japan, for heat exchangers in gas water heaters. ${ }^{46)}$ One module consisting of 54 pairs of oxide $p-n$ legs surrounds a metal pipe, in which water flows to keep the temperature difference. The surfaces of the modules are heated up to ca. $1000^{\circ} \mathrm{C}$ by the flames of natural gas combustion. One pipe-type module can

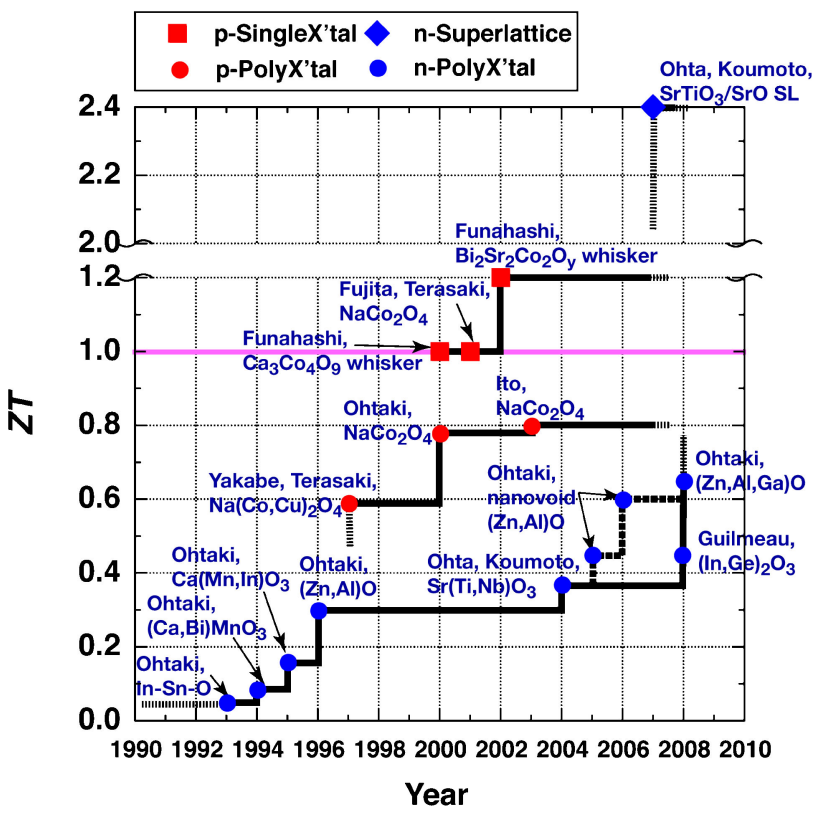

Fig. 7. (Color online) The timeline for the highest $Z T$ of oxide thermoelectric materials.

generate an electricity of $0.28 \mathrm{~W}$. According to the report, Type24 gas water heaters widely used for individual houses in Japan can be equipped with 60 of the pipe-type modules, and aided by reduction of internal resistance of the modules and improved heat conduction, power generation of $800 \mathrm{~W}$ is expected.

On fabricating modules, one of the major drawbacks of oxide materials is that it is difficult to obtain both $n$ - and $p$-type materials from the same mother compound. There are some other technical issues such as stability of high temperature junctions, material selection and jointing for electrodes and current collectors, and mismatch of thermal expansion coefficient of the module components, etc. Nevertheless, oxide thermoelectric modules are very attractive, because they can utilize conventional ceramic processes, can be used directly at high temperature or in combustion flames, and are durable, non-toxic, and low cost.

Recently, it was reported that two-dimensional electron gas (2-DEG) formed at the interfaces of a superlattice structure made by $\mathrm{SrTiO}_{3}$ epitaxial thin films showed $Z T \approx 2.4 .{ }^{47)}$ Towards the independent control of electrons and phonons, a large diversity of the crystal structures and conduction mechanisms in oxides as well as nanostructure controls are becoming more and more important. Figure 7 depicts the history of oxide thermoelectric materials. Recovery of unused waste heat by oxide thermoelectric modules is anticipated to be realized in the near future.

\section{References}

1) "CRC Handbook of Thermoelectrics", CRC Press, Inc., Boca Raton (1995).

2) M. Ohtaki, D. Ogura, K. Eguchi and H. Arai, J. Mater. Chem., 4, 653-656 (1994).

3) D. Berardan, E. Guilmeau, A. Maignan and B. Raveau, Solid State Commun., 146, 97-101 (2008).

4) D. P. Karim and A. T. Aldred, Phys. Rev. B, 20, 2255-2263 (1979).

5) W. J. Weber, C. W. Griffin and J. L. Bates, J. Am. Ceram. Soc., 70, 265-270 (1987).

6) C. Wood and D. Emin, Phys. Rev. B, 29, 4582-4587 (1984).

7) M. Ohtaki, H. Koga, K. Eguchi and H. Arai, Proc. 13th Int. 
Conf. Thermoelectrics, AIP Conference Proceedings No. 316, American Institute of Physics (1995) pp. 115-118.

8) M. Ohtaki, H. Koga, T. Tokunaga, K. Eguchi and H. Arai, J. Solid State Chem., 120, 105-111 (1995).

9) M. Ohtaki, T. Tokunaga, K. Eguchi and H. Arai, Proc. 16th Int. Conf. Thermoelectrics, IEEE Catalog Number 97TH8291, IEEE, Piscataway (1997) pp. 224-227.

10) D. Flahaut, T. Mihara, R. Funahashi, N. Nabeshima, K. Lee, H. Ohta and K. Koumoto, J. Appl. Phys., 100, 084911 (2006).

11) S. Urata, R. Funahashi, T. Mihara, A. Kusuge, S. Sodeoka and T. Tanaka, Int. J. Appl. Ceram. Technol., 4, 535-540 (2007).

12) X. Y. Huang, Y. Miyazaki and T. Kajitani, Solid State Commun., 145, 132-136 (2008).

13) L. D. Hicks and M. S. Dresselhaus, Phys. Rev. B, 47, $12727-$ 12731 (1993).

14) L. D. Hicks and M. S. Dresselhaus, Phys. Rev. B, 47, 1663116634 (1993).

15) I. Terasaki, Y. Sasago and K. Uchinokura, Phys. Rev. B, 56, R12685-R12687 (1997).

16) I. Terasaki, Kotai Butsuri, 33, 217-221 (1998) [in Japanese].

17) I. Terasaki, H. Mikami and R. Funahashi, Kinzoku, 74, 773778 (2004) [in Japanese].

18) I. Terasaki, Nippon Kessho Gakkaishi, 46, 27-31 (2004) [in Japanese].

19) Y. Ando, N. Miyamoto, K. Segawa, T. Kawata and I. Terasaki, Phys. Rev. B, 60, 10580-10583 (1999).

20) Y. Miyazaki, K. Kudo, M. Akoshima, Y. Ono, Y. Koike and T. Kajitani, Jpn. J. Appl. Phys., 39, L531-L533 (2000).

21) C. Masset, C. Michel, A. Maignan, M. Hervieu, O. Toulemonde, F. Studer, B. Raveau and J. Hejtmanek, Phys. Rev. B, 62, 166-175 (2000).

22) H. Leligny, D. Grebille, O. Pérez, A. C. Masset, M. Hervieu and B. Raveau, Acta Crystallogr., Sect. B: Struct. Sci., 56, 173$182(2000)$.

23) R. Funahashi and M. Shikano, Appl. Phys. Lett., 81, 14591461 (2002).

24) R. Funahashi, I. Matsubara, H. Ikuta, T. Takeuchi, U. Mizutani and S. Sodeoka, Jpn. J. Appl. Phys., 39, L1127-L1129 (2000).

$25)$ K. Fujita, T. Mochida and K. Nakamura, Jpn. J. Appl. Phys., 40, 4644-4647 (2001).

26) E. Maeda and M. Ohtaki, Trans. Mater. Res. Soc. Jpn., 25, 237-240 (2000).
27) M. Ito, T. Nagira, D. Furumoto, S. Katsuyama and H. Nagai, Scr. Mater, 48, 403-408 (2003).

28) D. Wang, L. Cheng, Q. Yao and J. Li, Solid State Commun., 129, 615-618 (2004).

29) L. F. Mattheiss, Phys. Rev. B, 6, 4718-4740 (1972).

30) H. Muta, K. Kurosaki and S. Yamanaka, J. Alloys Compd., 350, 292-295 (2003).

31) H. Obara, A. Yamamoto, C.-H. Lee, K. Kobayashi, A. Matsumoto and R. Funahashi, Jpn. J. Appl. Phys., 43, L540L542 (2004).

32) T. Okuda, N. Nakanishi, S. Miyasaka and Y. Tokura, Phys. Rev. $B, 63,113104$ (2001).

33) S. Ohta, T. Nomura, H. Ohta and K. Koumoto, J. Appl. Phys., 97, 034106 (2005).

34) S. Ohta, T. Nomura, H. Ohta, M. Hirano, H. Hosono and K. Koumoto, Appl. Phys. Lett., 87, 092108 (2005).

35) S. Ohta, H. Ohta and K. Koumoto, J. Ceram. Soc. Japan, 114, 102-105 (2006).

36) M. Ohtaki, T. Tsubota, K. Eguchi and H. Arai, J. Appl. Phys., 79, 1816-1818 (1996).

37) T. Tsubota, M. Ohtaki, K. Eguchi and H. Arai, J. Mater. Chem., 7, 85-90 (1997).

38) T. Tsubota, M. Ohtaki, K. Eguchi and H. Arai, Proc. 16th Int. Conf. Thermoelectrics, IEEE, Piscataway (1997) pp. 240-243.

39) T. Tsubota, M. Ohtaki, K. Eguchi and H. Arai, J. Mater. Chem., 8, 409-412 (1998).

40) M. Ohtaki, T. Tsubota and K. Eguchi, Proc. 17th Int. Conf. Thermoelectrics, IEEE, Piscataway (1998) pp. 610-613.

41) S. Katsuyama, Y. Takagi, M. Ito, K. Majima, H. Nagai, H. Sakai, K. Yoshimura and K. Kosuge, J. Appl. Phys., 92, 13911398 (2002).

42) M. Ohtaki, Mater. Integr., 13, 27-32 (2000) [in Japanese].

43) P. Wagner and R. Helbig, J. Phys. Chem. Solids, 35, 327-335 (1974).

44) G. A. Slack, Phys. Rev. B, 6, 3791-3800 (1972).

45) M. Ohtaki, K. Araki and K. Yamamoto, J. Electron. Mater., 38, 1234-1238 (2009).

46) R. Funahashi and S. Urata, Int. J. Appl. Ceram. Technol., 4, 297-307 (2007).

47) H. Ohta, S. Kim, Y. Mune, T. Mizoguchi, K. Nomura, S. Ohta, T. Nomura, Y. Nakanishi, Y. Ikuhara, M. Hirano, H. Hosono and K. Koumoto, Nat. Mater., 6, 129-134 (2007). 